\title{
Reduction in psychotic symptoms as a predictor of patient satisfaction with antipsychotic medication in schizophrenia: Data from a randomized double-blind trial Georges M Gharabawi1 ${ }^{1}$ Andrew Greenspan*2, Marcia FT Rupnow ${ }^{3}$, Colette Kosik-Gonzalez ${ }^{1}$, Cynthia A Bossie ${ }^{1}$, Young Zhu ${ }^{4}$, Amir H Kalali ${ }^{5,6}$ and A George Awad ${ }^{7}$
}

Address: ${ }^{1}$ Medical Affairs, Janssen Pharmaceutica Inc., Titusville, NJ, USA, ${ }^{2}$ Johnson \& Johnson Pharmaceutical Research and Development, Titusville, NJ, USA, ${ }^{3}$ Outcomes Research, Ortho-McNeil Janssen Scientific Services, L.L.C., Titusville, NJ, USA, ${ }^{4}$ Quantitative Methodology, OrthoMcNeil Janssen Scientific Services, L.L.C., Titusville, NJ, USA, ${ }^{5}$ Quintiles CNS Therapeutics, San Diego, California, USA, ${ }^{6}$ University of California, San Diego, California, USA and ${ }^{7}$ University of Toronto, Toronto, Ontario, Canada

Email: Georges M Gharabawi - Ggharaba@janus.jnj.com; Andrew Greenspan* - agreensp@prdus.jnj.com;

Marcia FT Rupnow - mrupnow1@omjus.jnj.com; Colette Kosik-Gonzalez - ckosikgo@janus.jnj.com; Cynthia A Bossie - cbossie@janus.jnj.com; Young Zhu - Yzhu6@omjus.jnj.com; Amir H Kalali - Amir.kalali@quintiles.com; A George Awad - GAwad@HRRH.ON.CA

* Corresponding author

Published: 20 October 2006

BMC Psychiatry 2006, 6:45 doi:10.1186/147/-244X-6-45
Received: 23 May 2006

Accepted: 20 October 2006

This article is available from: http://www.biomedcentral.com/I47I-244X/6/45

(c) 2006 Gharabawi et al; licensee BioMed Central Ltd.

This is an Open Access article distributed under the terms of the Creative Commons Attribution License (http://creativecommons.org/licenses/by/2.0), which permits unrestricted use, distribution, and reproduction in any medium, provided the original work is properly cited.

\begin{abstract}
Background: Patient satisfaction with antipsychotic treatment is important. Limited evidence suggests that satisfaction is associated with symptom improvement and compliance. Predictors of patient satisfaction with antipsychotic medication were examined in a study of patients with a recent exacerbation of schizophrenia.

Methods: Data are from a randomized, double-blind trial comparing risperidone $(n=152)$, quetiapine $(n=156)$, and placebo $(n=73)$. Medication Satisfaction Questionnaire (MSQ) was completed after 14 days of treatment and after 6 weeks at last study visit.

Results: Medication satisfaction at both time points was significantly associated in multiple regression analysis with improvement on 3 Positive and Negative Syndrome Scale (PANSS) factor scores (positive symptoms $p<.01$; uncontrolled hostility/excitement, $\mathrm{p}<.0005$; anxiety/depression, $\mathrm{p}<.04)$ and treatment with risperidone $(\mathrm{p}<$ $.03)$; at day 14 , significant association was also found with older age $(p=.0 \mathrm{I})$. At both time points, predictor variables explained over $30 \%$ of the variance in medication satisfaction. Change in Hamilton Depression Scale, prolactin levels, sex, and reported adverse events of extrapyramidal symptoms, sedation, and movement disorders were not significant predictors of satisfaction. Lower level of medication satisfaction at day 14 was associated with earlier discontinuation in the trial at week 6 end point. A focused principal components analysis of PANSS factors and MSQ suggested that medication satisfaction relates to 3 groups of factors in descending order of magnitude: lower levels of (a) uncontrolled hostility/excitement, (b) positive symptoms, and (c) negative symptoms, disorganized thoughts, and anxiety/depression.
\end{abstract}

Conclusion: Results give further support that treatment satisfaction is positively associated with symptom improvement, particularly psychotic symptoms, and suggest that satisfaction may also be related to compliance, as those who were more satisfied remained in the trial for a longer period of time.

Trial registration number: Trial registration number NCT0006/802 


\section{Background}

Patient satisfaction with antipsychotic treatment is an important outcome. There is limited evidence suggesting that it is positively associated with compliance [1], improved clinical outcomes [2-6], and quality of life [7]. Yet there is a lack of prospective studies examining the association of patient satisfaction, medication compliance, and treatment outcomes [8].

While considerable attention has been given to the efficacy and safety of second-generation antipsychotics, little attention in clinical trials has been given to medication compliance, subjective tolerability, and satisfaction with treatment $[9,10]$. There are some data from naturalistic studies suggesting greater satisfaction among patients treated with second-generation than first-generation antipsychotic medications [11,12]. It is surprising that patient satisfaction, which may be a key advantage of second-generation antipsychotics, has not received adequate research attention. This has led to the recognition that there is a need for well-designed studies of treatment satisfaction of second-generation antipsychotic medications before firm conclusions can be reached [13]. In the current study, we examined predictors and consequences of patient satisfaction with atypical antipsychotic medication in a study of patients with a recent exacerbation of schizophrenia treated with risperidone, quetiapine, or placebo.

\section{Methods}

\section{Study design}

Data are from a 2-phase, double-blind, international, 6week study conducted at 30 sites. The safety and efficacy results and methodology are reported elsewhere [14]. Inpatients with schizophrenia or schizoaffective disorder with a recent exacerbation of psychotic symptoms were randomly assigned to receive risperidone, quetiapine, or placebo in a 2:2:1 ratio. Patients were treated with risperidone, quetiapine, or placebo monotherapy for the first 2 weeks; during the subsequent 4 weeks, investigators were permitted to prescribe additional psychiatric medications as necessary. Study medications were increased from days 1 to 5 according to a fixed schedule. Target doses at day 5 were 4 or $6 \mathrm{mg} /$ day of risperidone and 400 or $600 \mathrm{mg} /$ day of quetiapine. On day 8 , the dose of quetiapine could be increased, in a blinded fashion, to 600 or $800 \mathrm{mg} / \mathrm{day}$. Patients were maintained on their day- 8 dose for the remainder of the study. Mean doses at day 14 were $4.7 \pm$ $0.9 \mathrm{mg} /$ day of risperidone and $579.5 \pm 128.9 \mathrm{mg} /$ day of quetiapine. Dosing regimens for risperidone and quetiapine were in accordance with the prescribing information for each drug and also reflected clinical and research practices for treating patients with acute exacerbations of schizophrenia $[15,16]$.
The trial was conducted in accordance with current International Conference on Harmonization-Good Clinical Practice guidelines and the Declaration of Helsinki and its subsequent revisions. All patients deemed competent by the investigator provided written informed consent prior to study participation. If a patient was deemed not legally competent, then consent was obtained from the patient and an authorized representative. Ethical approval was obtained by Institutional Review Boards at each investigators site.

Exclusion criteria included a co-morbid Axis I diagnosis (with the exception of substance abuse/dependence), borderline personality disorder, mental retardation, or a clinically significant medical illness. Also excluded were patients who had received risperidone or quetiapine within 7 days of baseline, clozapine within 60 days, or depot antipsychotics or electroconvulsive therapy within defined time periods.

Baseline characteristics were similar in the 3 treatment arms [14]. The mean ( \pm SD) age of patients was $34.8 \pm 9.7$ (median 35; range 18-63) years, and 60\% were male. The mean $( \pm$ SD) baseline Positive and Negative Syndrome Scale (PANSS) was $95.8 \pm 18.5$ and Clinical Global Impressions (CGI)-Severity was $5.4 \pm 0.5$. Eighty-seven percent of the patients completed the day 14 visit and $75 \%$ completed day 42 .

\section{Efficacy and safety assessment}

Assessments were conducted on days 1, 3, 5, 7, 9, 14, 21, 28, and 42. Efficacy measures included the PANSS [17]; the 17-item Hamilton-Depression Scale (HAM-D) [18]; and the CGI-Severity and CGI-Change scales [19]. Safety measures included the Simpson Angus Scale (SAS) [20] and the Barnes Akathisia Scale (BAS) [21], which were administered at baseline, day 14, 28, and 42. Reports of adverse events were collected at all visits, and laboratory assessments (including prolactin) were performed at baseline and days 14 and 42 .

\section{Medication satisfaction}

Patient satisfaction with the study medication was assessed using the Medication Satisfaction Questionnaire (MSQ) a 1-item global patient-rated scale. Specifically, patients were asked to respond on a 7 -point scale, ranging from extremely dissatisfied (1) to extremely satisfied (7), to the following: "The way you feel about taking your study medication is". The MSQ was derived from work using a much longer and more detailed published scale [22] and is similar to items included in other scales [3]. There has been much debate in the field regarding the correct methodological approach for measuring patient satisfaction and no consensus has yet been reached. It has been argued that lengthier scales typically contain a large 
Table I: Predictors of patient satisfaction with antipsychotic medication

\begin{tabular}{|c|c|c|c|c|c|c|c|c|c|c|}
\hline & \multicolumn{5}{|c|}{ Day 14} & \multicolumn{5}{|c|}{ Day 42 (end point) } \\
\hline & \multicolumn{3}{|c|}{ Univariate regression } & \multicolumn{2}{|c|}{$\begin{array}{l}\text { Step-wise multiple } \\
\text { regression } R^{2}=.31\end{array}$} & \multicolumn{3}{|c|}{ Univariate regression } & \multicolumn{2}{|c|}{$\begin{array}{l}\text { Step-wise multiple } \\
\text { regression } \mathrm{R}^{2}=.33\end{array}$} \\
\hline & $\mathrm{T}=$ & $\mathrm{P}=$ & $\mathrm{R}^{2}$ & $\mathrm{~F}=$ & $P=$ & $\mathrm{T}=$ & $P=$ & $\mathrm{R}^{2}$ & $\mathrm{~F}=$ & $\mathrm{P}=$ \\
\hline $\begin{array}{l}\text { Symptom change } \\
\text { PANSS factors Positive }\end{array}$ & -10.11 & $<.0001$ & .26 & 21.98 & $<.0001$ & -9.40 & $<.0001$ & .23 & 6.39 & .01 \\
\hline Negative & -5.22 & $<.0001$ & .11 & & & -5.69 & $<.0001$ & .12 & 3.63 & .06 \\
\hline Disorganized thoughts & -5.89 & $<.0001$ & .13 & & & -5.64 & $<.0001$ & .12 & & \\
\hline Hostility/excitement & -9.25 & $<.0001$ & .23 & 14.11 & .0002 & -8.69 & $<.0001$ & .21 & 12.46 & .0005 \\
\hline Anxiety/depression & -5.80 & $<.0001$ & .13 & 4.03 & .04 & -7.43 & $<.0001$ & .17 & 16.85 & $<.0001$ \\
\hline HAM-D & -5.33 & $<.0001$ & .11 & & NS & -5.06 & $<.0001$ & .11 & & NS \\
\hline$\frac{\text { Adverse events }}{\text { Prolactin level }}$ & .439 & .66 & .04 & & & -.666 & .50 & .04 & & NS \\
\hline EPS reported & -.95 & .34 & .04 & 2.89 & .09 & .60 & .55 & .04 & & NS \\
\hline Sedation reported & -1.21 & .23 & .05 & & & 1.91 & .06 & .05 & & NS \\
\hline BAS global (present) & -1.42 & .16 & .05 & & & -.88 & .38 & .04 & & \\
\hline SAS total (present) & -.50 & .62 & .04 & & & -.25 & .80 & .04 & & \\
\hline Demographics Age & 1.84 & .07 & .05 & 6.17 & .01 & .58 & .56 & .04 & & \\
\hline Gender (male) & .46 & .64 & .04 & & & .37 & .71 & .04 & & \\
\hline Antipsychotic use & & $N A^{*}$ & & & & -2.69 & .007 & .06 & 8.03 & .004 \\
\hline Risperidone & 3.48 & .0006 & .04 & 4.80 & .03 & 3.06 & .002 & & 4.94 & .027 \\
\hline Quetiapine & 1.15 & .25 & .04 & .60 & .44 & .83 & .41 & & .00 & .98 \\
\hline
\end{tabular}

* Antipsychotic use appeals after 14 days.

Abbreviations: PANSS, Positive and Negative Syndrome Scale; HAM-D, Hamilton Depression Scale; NS, not significant; EPS, extrapyramidal symptoms; BAS, Barnes Akathisia Scale; SAS, Simpson Angus Scale.

number of items that are irrelevant and thus are more susceptible to providing inaccurate results. Longer instruments of patient satisfaction have generally not demonstrated better validity than 1 -item global ratings [23]. This is of particular relevance for acutely severely ill psychotic patients who could not reasonably be expected to complete a lengthy patient-rated instrument.

\section{Data analysis}

We attempted to predict medication satisfaction at days 14 and 42 using univariate linear regression followed by step-wise multiple linear regression. The predictor variables chosen were change from baseline in symptoms ( 5 PANSS factor scores [24] and HAM-D scale), treatment regimen (risperidone, quetiapine, or placebo), reported adverse events of extrapyramidal symptoms (EPS) or sedation, movement disorders (BAS, SAS), prolactin levels, age, and sex. We also examined whether greater initial treatment satisfaction as measured at day 14 was associated with time in trial to end point. This was done by computing the mean time (in days) in trial for each response category on the MSQ.

Finally, to understand the relationship between psychotic symptomatology and medication satisfaction we examined the association of the MSQ and the 5 PANSS factors
[24]. This was done first by examining the correlations of the MSQ and PANSS factors. To graphically represent and examine the relationship between Medication Satisfaction and the five PANSS factors we used focused principal components analysis (PCA) [25]. Focused PCA is a special type of PCA designed to describe and understand relationships between a set of quantitative variables, with a particular interest in the dependencies of one variable, in this case MSQ, with the others, in this case the PANSS factors. The relationships between nondependent variables are interpreted as in a PCA: correlated variables are close or diametrically opposite (for negative correlations); independent variables make a right angle with the origin. Focused PCA was conducted using R (version 2.0.1) software, module PSY (version 0.6).

\section{Results and Discussion}

As shown in Table 1, medication satisfaction at both time points was significantly associated with improvement (change from baseline to each time point) on 3 PANSS factor scores (positive symptoms, uncontrolled hostility/ excitement, anxiety/depression), treatment with risperidone, and at day 14 also higher age. At both time points, these predictor variables explained over $30 \%$ of the variance in medication satisfaction in a multiple regression analysis. Change in HAM-D scale, prolactin levels, sex, 


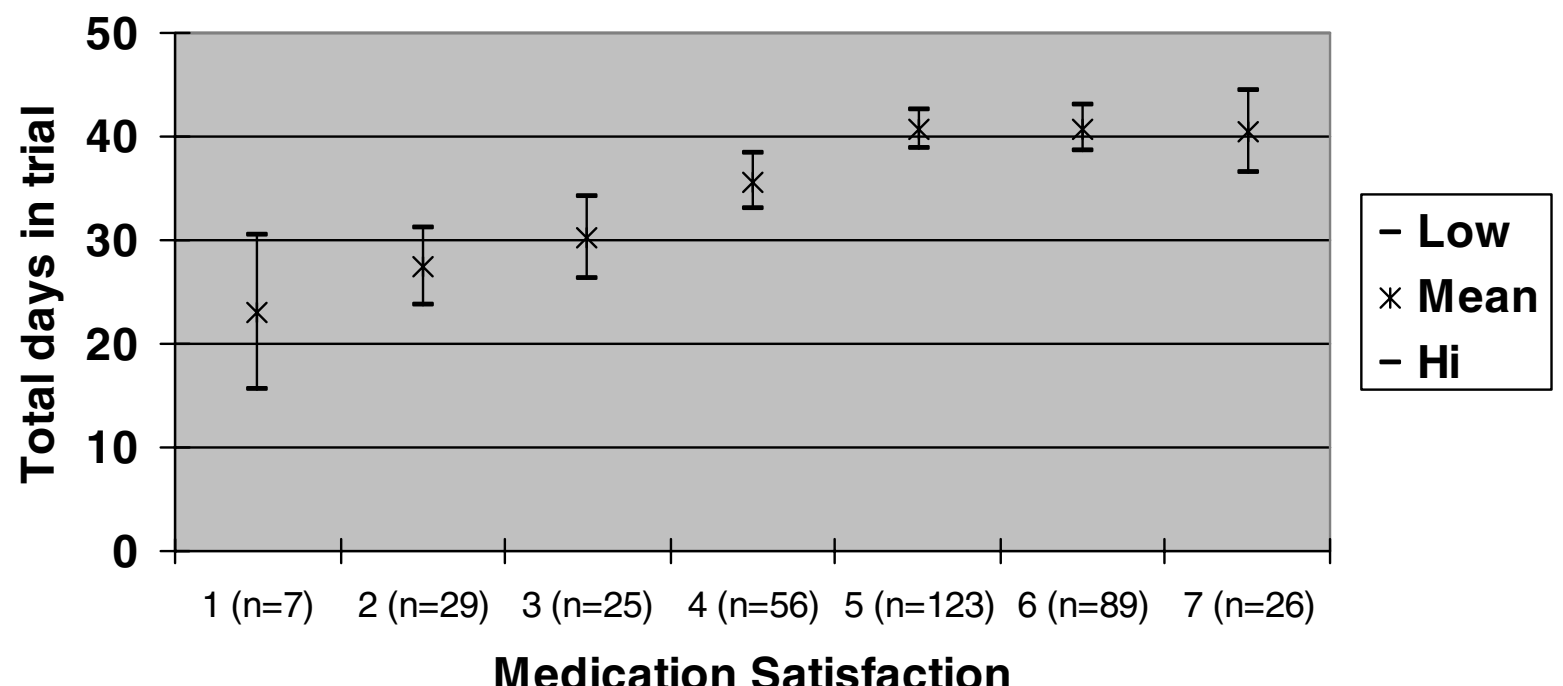

Figure I

Mean (95\% confidence interval) time (days) in trial by Medication Satisfaction after I4 days of treatment (I very dissatisfied; 7 very satisfied).

and reported adverse events of EPS, sedation, and movement disorders (BAS, SAS) were not significant predictors of satisfaction.

Figure 1 shows the mean time (in days) in trial until week 6 end point by medication satisfaction after 14 days of treatment. Patients who were satisfied clearly remained in the study significantly longer than those who were not satisfied.

The correlation of the PANSS factors and MSQ (Table 2) and the focused PCA (Figure 2) suggest that medication satisfaction relates to 3 groups of factors in descending order of magnitude: lower levels of (a) uncontrolled hostility/excitement, (b) positive symptoms, and (c) negative symptoms, disorganized thoughts, and anxiety/depression. In the focused PCA (Figure 2) as the rings get closer to the center they reflect a higher correlation with the MSQ. The positive symptoms factor and uncontrolled hostility/excitement were the most closely correlated with the MSQ, followed by negative symptoms and disorganized thoughts, with little association with anxiety/depression.

\section{Conclusion}

The results give further support that treatment satisfaction is positively associated with symptom improvement, particularly psychotic symptoms. The results also suggest that treatment satisfaction may also be related to compliance, since patients who were more satisfied remained in the trial for a longer time. A single-item measure of patient satisfaction was sensitive to clinical improvement and adherence. Patient-reported outcomes, such as satisfaction with medications, offer a way of measuring both efficacy and tolerability features of treatments from a patient perspective. As rated by the MSQ, data suggest that the significantly greater patient satisfaction with risperidone than quetiapine or placebo may be related to the greater symptom reduction associated with risperidone. This is suggested by both regression models in which a reduction in psychotic symptoms consistently emerged as a significant predictor of medication satisfaction. Further, in the multiple regression model, treatment with risperidone, but not quetiapine, and increasing age were also predictive of medication satisfaction. Our finding that patient satisfaction is related to improvement of positive symptoms and not negative symptoms might be related to the duration of the trial. As was the case in this trial, within 6 weeks, positive symptoms usually decline much more than negative or other symptoms. While certain safety issues are often cited as limiting factors for patient acceptability, neither movement disorders measures nor prolactin elevation was predictive of medication satisfaction.

Table 2: Correlation of PANSS factors (change from baseline score) and medication satisfaction at day $14(n=381)$

\begin{tabular}{lcc}
\hline & $r=$ & $\mathrm{P}<$ \\
\hline Uncontrolled hostility/excitement & -.44 & .00001 \\
Positive symptoms & -.39 & .00001 \\
Negative symptoms & -.30 & .00001 \\
Disorganized thoughts & -.30 & .00001 \\
Anxiety/depression & -.14 & .015 \\
\hline
\end{tabular}

Abbreviations: PANSS, Positive and Negative Syndrome Scale. 


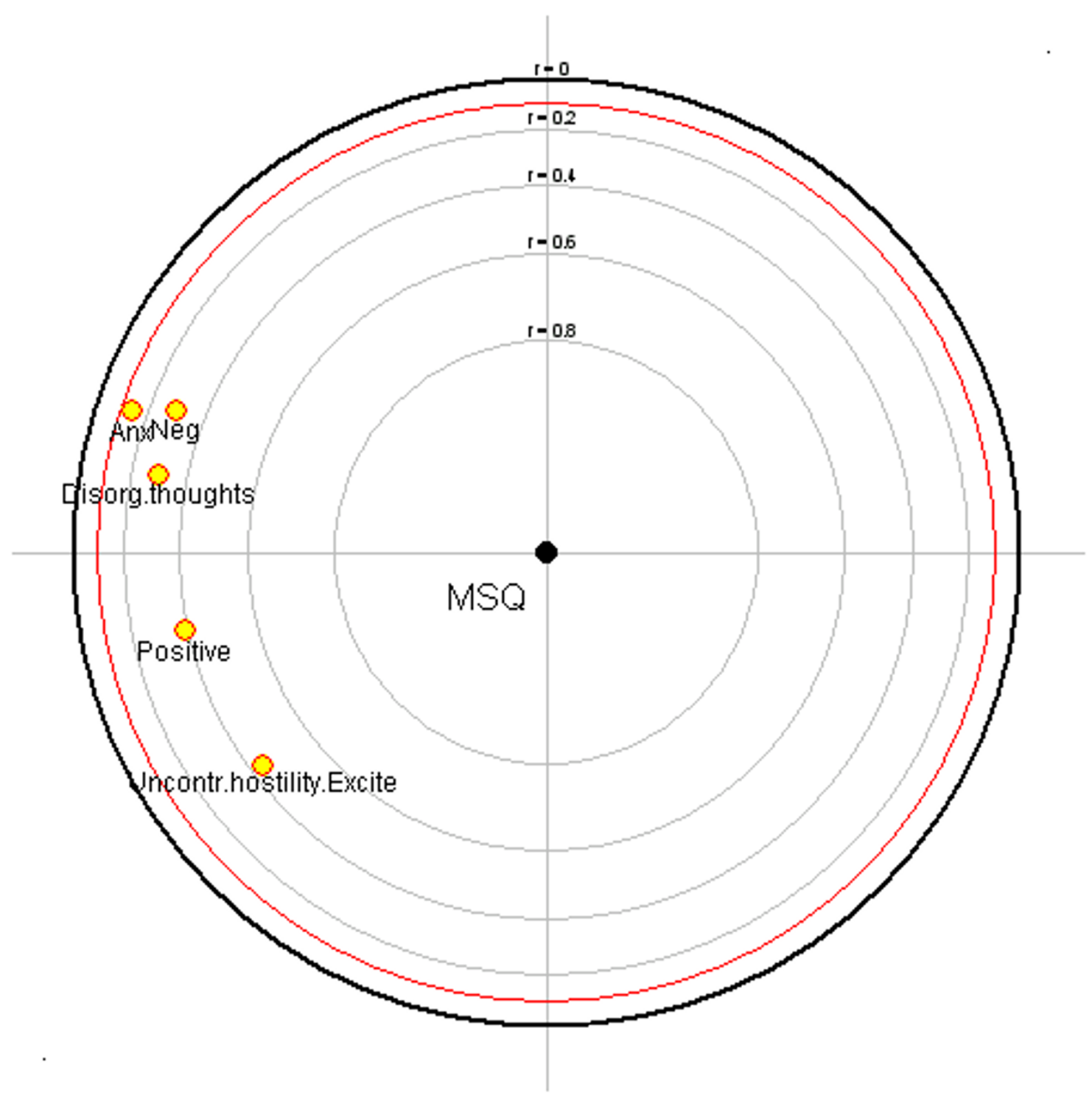

Figure 2

Focused principal components analysis of MSQ and PANSS factors. Abbreviations: MSQ, Medication Satisfaction Questionnaire; PANSS, Positive and Negative Syndrome Scale. As the rings get closer to the center they reflect a higher correlation with MSQ.

Future studies of second-generation antipsychotic medications should routinely include measures of medication satisfaction. Unlike the current study, in which the measure was only administered at 2 time points, consideration should be given to measuring satisfaction each time efficacy is measured. With the advent of yet improved formulations and long-acting medications designed to improve compliance, medication satisfaction will be an outcome of major importance.

\section{Competing interests}

GG declares he is an employee of Janssen, the company which funded the research, manuscript development, and the journal's article processing charge. GG is a J\&J stockholder.

AG declares he is an employee of Johnson \& Johnson Pharmaceutical Research and Development. AG is a J\&J stockholder. 
MR declares she is an employee of Janssen, the company which funded the research, manuscript development, and the journal's article processing charge. MR is a J\&J stockholder.

CKG declares she is an employee of Janssen, the company which funded the research, manuscript development, and the journal's article processing charge. CKG is a J\&J stockholder.

CB declares she is an employee of Janssen, the company which funded the research, manuscript development, and the journal's article processing charge. CB is a J\&J stockholder.

$\mathrm{YZ}$ declares he is an employee of Janssen, the company which funded the research, manuscript development, and the journal's article processing charge. YZ is a J\&J stockholder.

AK declares he is on the Janssen Speakers Bureau

AGA declares that he has no competing interests

\section{Authors' contributions}

GG: Study conception and design, analysis plan, interpretation of data, input for manuscript revision.

AG: Acquisition of the data, analysis plan, interpretation of data, drafting and revising the manuscript.

MFTR: Study design, interpretation of data, input for manuscript revision.

CKG: Study design, acquisition of the data, interpretation of data, input for manuscript revision.

CB: Analysis plan, interpretation of data, drafting and revising the manuscript.

YZ: Analysis, input for manuscript revision.

AHK: Interpretation of data, input for manuscript revision.

AGW: Interpretation of data, input for manuscript revision.

All authors read and approved the final manuscript.

\section{Acknowledgements}

The study and analyses were funded by Janssen LP. Employees of Janssen are coauthors on the manuscript and thus had a role in the writing and decision to submit. The authors wish to acknowledge the technical and editorial assistance provided by Jonathan Rabinowitz (funded by Janssen LP).

\section{References}

I. Hogan TP, Awad AG, Eastwood R: A self-report scale predictive of drug compliance in schizophrenics: reliability and discriminative validity. Psychol Med 1983, I3:177-183.

2. Hogan TP, Awad AG: Subjective response to neuroleptics and outcome in schizophrenia: a re-examination comparing two measures. Psychol Med 1992, 22:347-352.

3. Van Putten T, May PR: Subjective response as a predictor of outcome in pharmacotherapy: the consumer has a point. Arch Gen Psychiatry 1978, 35:477-480.

4. Kelstrup A, Lund K, Lauritsen B, Bech P: Satisfaction with care reported by psychiatric inpatients: relationship to diagnosis and medical treatment. Acta Psychiatr Scand I993, 87:374-379.

5. Druss BG, Rosenheck RA, Stolar M: Patient satisfaction and administrative measures as indicators of the quality of mental health care. Psychiatr Serv 1999, 50:1053-1058.

6. Greenwood N, Key A, Burns T, Bristow M, Sedgwick P: Satisfaction with in-patient psychiatric services. Relationship to patient and treatment factors. Br J Psychiatry I999, I74:159-163.

7. Hofer A, Kemmler G, Eder U, Edlinger M, Hummer M, Fleischhacker WW: Quality of life in schizophrenia: the impact of psychopathology, attitude toward medication, and side effects. J Clin Psychiatry 2004, 65:932-939.

8. Hogan TP, Awad AG: Drug Attitude Inventory in Handbook of Psychiatric Measures Washington, DC: American Psychiatric Association; 2000.

9. Kalali A: Patient satisfaction with, and acceptability of, atypical antipsychotics. Curr Med Res Opin 1999, I 5:135-137.

10. Awad AG, Voruganti LN: New antipsychotics, compliance, quality of life, and subjective tolerability - are patients better off? Can J Psychiatry 2004, 49:297-302.

II. Ritsner M, Perelroyzen G, Ilan H, Gibel A: Subjective response to antipsychotics of schizophrenia patients treated in routine clinical practice: a naturalistic comparative study. J Clin Psychopharmacol 2004, 24:245-254.

12. Rabinowitz J, Bromet EJ, Davidson M: Short report: comparison of patient satisfaction and burden of adverse effects with novel and conventional neuroleptics: a naturalistic study. Schizophr Bull 200I, 27:597-600.

13. Jayaram MB, Hosalli P: Risperidone versus olanzapine for schizophrenia. Cochrane Database Syst Rev 2005, 2:CD005237.

14. Potkin SG, Gharabawi GM, Greenspan AJ, Mahmoud R, KosikGonzalez C, Rupnow MF, Bossie CA, Davidson M, Burtea V, Zhu Y, Trivedi JK: A double-blind comparison of risperidone, quetiapine, and placebo in patients with schizophrenia experiencing an acute exacerbation requiring hospitalization. Schizophr Res 2006, 85:254-265.

15. Lieberman JA, Stroup TS, McEvoy JP, Swartz MS, Rosenheck RA, Perkins DO, Keefe RS, Davis SM, Davis CE, Lebowitz BD, Severe J, Hsiao JK, Clinical Antipsychotic Trials of Intervention Effectiveness (CATIE) Investigators: Effectiveness of antipsychotic drugs in patients with chronic schizophrenia. N Engl J Med 2005, 353:I209-I 223.

16. Stroup TS, McEvoy JP, Swartz MS, Byerly MJ, Glick ID, Canive JM, McGee MF, Simpson GM, Stevens MC, Lieberman JA: The National Institute of Mental Health Clinical Antipsychotic Trials of Intervention Effectiveness (CATIE) project: schizophrenia trial design and protocol development. Schizophr Bull 2003, 29:|5-3|.

17. Kay SR, Fiszbein A, Opler LA: The positive and negative syndrome scale (PANSS) for schizophrenia. Schizophr Bull 1987, |3:26|-276.

18. Hamilton M: A rating scale for depression. J Neurol Neurosurg Psych 1960, 23:56-62.

19. Guy W: Clinical Global Impression (CGI) in Handbook of Psychiatric Measures Edited by: Rush AJ. Washington, DC: American Psychiatric Association; 2000.

20. Simpson GM, Angus JW: A rating scale for extrapyramidal side effects. Acta Psychiatr Scand Suppl 1970, 2 I 2: I I- 19.

21. Barnes TRE: Barnes Akathisia Rating Scale (BARS) in Handbook of Psychiatric Measures Edited by: Rush AJ. Washington, DC: American Psychiatric Association; 2000.

22. Atkinson MJ, Sinha A, Hass SL, Colman SS, Kumar RN, Brod M, Rowland CR: Validation of a general measure of treatment satisfaction, the Treatment Satisfaction Questionnaire for Medication (TSQM), using a national panel study of chronic disease. Health Qual Life Outcomes 2004, 2: 12. 
23. Sitzia J: How valid and reliable are patient satisfaction data? An analysis of 195 studies. Int J Qual Health Care 1999, II:319-328.

24. Marder SR, Davis JM, Chouinard G: The effects of risperidone on the five dimensions of schizophrenia derived by factor analysis: combined results of the North American trials. J Clin Psychiatry 1997, 58:538-546.

25. Falissard B: Focused Principal Component Analysis: looking at a correlation matrix with a particular interest in a given variable. Journal of Computational and Graphical Statistics 1999, 8:906-912.

\section{Pre-publication history}

The pre-publication history for this paper can be accessed here:

http://www.biomedcentral.com/1471-244X/6/45/pre

pub

Publish with Bio Med Central and every scientist can read your work free of charge

"BioMed Central will be the most significant development for disseminating the results of biomedical research in our lifetime. "

Sir Paul Nurse, Cancer Research UK

Your research papers will be:

- available free of charge to the entire biomedical community

- peer reviewed and published immediately upon acceptance

- cited in PubMed and archived on PubMed Central

- yours - you keep the copyright

Submit your manuscript here:

http://www.biomedcentral.com/info/publishing_adv.asp 